View Article Online / Journal Homepage / Table of Contents for this issue

SMITHELLS : FLUORINE COMPOUNDS OF URANIUM.

125

XVII.-On Some Fluorine Compounds of Uranium.

By Arthur Smithelds, B.Sc. (Dalton Scholar in the Laboratory of The Owens College).

I. Since the preparation of uranium oxyfluoride by Berzelius, the fluorine compounds of uranium have been investigated by Carrington Bolton (Zeitschr. f. Chem. [2], 353 ; Bull. Soc. Chim., 1866, 2, 450) and more recently by Ditte (Compt. rend., 91, 115). As the results obtained by these two chemists do not agree, the present experiments 
were undertaken at the suggestion of Professor Roscoe, in order to clear up the question.

The starting point in both the above cited researches was green uranoso-uranic oxide, $\mathrm{U}_{3} \mathrm{O}_{8}$. By the action of aqueous hydrofluoric acid on this body a voluminous green powder and a clear bright yellow solution are produced. The green powder, according to Bolton, is uranous fluoride, $\mathrm{UF}_{4}$, whilst the yellow solution upon evaporation gires an almost white amorphous mass, possessing the physical properties of a body obtained by Berzelius (Lehrb. d. Chem., $3,1099)$ by the action of hydrofluoric acid on uranic hydrate, and to which he assigned the formula $\mathrm{UO}_{2} \mathrm{~F}_{2}$. The equation representing the action of hydrofluoric acid on the green oxide would therefore be :-

$$
\mathrm{UO}_{2}, 2 \mathrm{UO}_{3}+8 \mathrm{HF}=\mathrm{UF}_{4}+2 \mathrm{UO}_{2} \mathrm{~F}_{2}+4 \mathrm{H}_{2} \mathrm{O} \text {. }
$$

Ditte on the other hand assigns to the green powder the formula $\mathrm{UO}_{2} \mathrm{~F}_{2}$, with the name uranyl fluoride. His description of the physical and chemical properties of the substance agrees with that of Bolton, but in addition he noticed a decomposition on heating in a closed crucible, viz., the formation of a white crystalline sublimate. With regard to the yellow solution, Ditte states that it is essentially a solution of uranium hexfluoride, and that on evaporation transparent yellow crystals are deposited, which when dried at $100^{\circ} \mathrm{C}$. have the formula $\mathrm{UF}_{6}, 8 \mathrm{HF}$. From these crystals he obtains the pure hexfluoride by calcining in a crucible until partial decomposition en sues, then extracting with water, and crystallising the $\mathrm{UF}_{6}$. The equation representing the action of hydrofluoric acid on the green oxide is given by him as follows :-

$$
\mathrm{U}_{3} \mathrm{O}_{8}+18 \mathrm{HF}=2\left(\mathrm{UF}_{6}, 2 \mathrm{HF}\right)+\mathrm{UO}_{2} \mathrm{~F}_{2}+6 \mathrm{H}_{2} \mathrm{O}+\mathrm{H}_{2} \text {. }
$$

He states that this may be verified by heating a known weight of $\mathrm{U}_{3} \mathrm{O}_{8}$ with hydrofluoric acid and weighing the resulting compounds, and that the rationale of the reaction is the splitting up of the $\mathrm{U}_{3} \mathrm{O}_{8}$ into $\mathrm{UO}_{2}$ and $\mathrm{UO}_{3}$; the former, acting as a simple body unites with the fluorine of the hydrofluoric acid, setting hydrogen free. The $\mathrm{UO}_{3}$ gives an acid hexfluoride and water.

\section{Action of $\mathrm{Hydrofuoric}$ Acid on the Green Oxide, $\mathrm{U}_{3} \mathrm{O}_{8}$.}

That the above equation given by Ditte is unlikely to express the reaction, may be argued from the fact that the liberation of hydrogen from an acid by the action of a metallic oxide is contrary to all experience. And again, the confirmation by weighing the products from a known weight of the green oxide will not hold good, for as will afterwards be evident, the only one capable of being weighed with 
accuracy is the green powder. If Bolton's formula be correct, one molecule of $\mathrm{U}_{3} \mathrm{O}_{8}(=848)$ gives one molecule of $\mathrm{UF}_{4}(310)$, and by Ditte's equation one molecule of $\mathrm{U}_{3} \mathrm{O}_{8}(=848)$ gives one molecule of $\mathrm{UO}_{2} \mathrm{~F}_{2}(=316)$. The difference here, which amounts to about 0.7 per cent., is evidently too small to render the operation a means of verifying either theory, even if it could be conducted accurately.

The question as to the evolution of hydrogen in the reaction was decided experimentally by treating 100 grams of the green oxide in a leaden retort with aqueous hydrofluoric acid, and collecting the evolved gases (if any) over a pneumatic trough. In Ditte's equation one molecule of $\mathrm{U}_{3} \mathrm{O}_{8}(848)$ gives one molecule of hydrogen, so that 100 grams should yield $\frac{22 \cdot 3 \times 100}{848}=2 \cdot 6$ litres of hydrogen. In my experiment considerable heat was evolved by the chemical action, and rather less than a quarter of a litre of gas passed into the collecting cylinder. This on examination proved to be air expanded from the hot retort. In order to confirm the conclusion that no hydrogen is liberated during the reaction, the experiment was repeated, the delivery-tube of the retort being carried to the top of the receiving cylinder, and after the air had been expelled into the latter as before, the apparatus was allowed to cool in situ. The result was that only an inappreciable quantity of air was left in the cylinder. It is true that effervescence is sometimes noticeable when the green oxide is treated with hydrofluoric acid; but this is due to the heat of chemical action expelling the air which is entangled in the fine powder, and is not observable if the action proceeds slowly.

\section{Uranous Flluoride, $\mathrm{UF}_{4}$.}

After the reaction just described, the retort contained the green powder and yellow solution. The two were separated, and the powder washed with distilled water-a very tedious process, as the substance either passes through the pores of the filter-paper or fills them up. After washing for a few days in this manner, the green powder was usually transferred to a large beaker and washed for a long time by decantation. The difficulty of getting rid of the last traces of hydroluoric acid is very great. When this had been accomplished as nearly as possible, the substance was dried at $100^{\circ}$ until no further loss of weight ensued.

In the analyses to be quoted, the uranium was usually determined by means of ammonium sulphide, the mixed sulphur and uranous oxide being very strongly ignited and weighed as $\mathrm{U}_{2} \mathrm{O}_{5}$. This process gave most satisfactory results when all the precautions mentioned by Remelé (Zeits. Anal. Chem., 4, 379) and Zimmerman

VOL. XIIII. 
(Annalen Chem., 204, 204) were observed. Sometimes in the case of a soluble fluoride, the uranium was determined by evaporating with sulphuric acid, adding excess of ammonium carbonate, again evaporating, and finally igniting to the oxide. In all determinations the uranium was weighed as $\mathrm{U}_{2} \mathrm{O}_{5}$, which being the final product of the application of intense heat to the other oxides, can easily be obtained pure. Fluorine was in all cases determined as calcium fluoride in the usual way. The total hydrogen (existing as water or in acid combination) was estimated by heating with anhydrous sodium carbonate and weighing the water absorbed by a calcium chloride tube (Bunsen).

The green powder was fused with sodium carbonate and the constituents determined with the following results:-

$$
\begin{aligned}
& \left.0.8645 \text { gram gave } 0.7450 \text { gram } \mathrm{U}_{2} \mathrm{O}_{5}=73.87\right\} \text { Mean }=74.03 \\
& 1 \cdot 2240, \quad, \quad 1 \cdot 0595, \quad, \quad=74 \cdot 19\} \text { per cent. U. } \\
& \left.0.5440 \quad, \quad, \quad 0.2785 \quad, \quad \mathrm{CaF}_{2}=24.94\right\} \text { Mean }=25.73 \\
& 0.5480 \quad " \quad " \quad 0.2985 \quad " \quad, \quad=26.53\} \text { per cent. F. }
\end{aligned}
$$

\begin{tabular}{|c|c|c|c|}
\hline \multirow[b]{2}{*}{ U } & \multirow[b]{2}{*}{$\begin{array}{l}\text { Found. } \\
74.03\end{array}$} & \multicolumn{2}{|c|}{ Calculated. } \\
\hline & & $\begin{array}{c}\mathrm{UF}_{4} \text { (Bolton). } \\
75 \cdot 95\end{array}$ & $\begin{array}{c}\mathrm{UO}_{2} \mathrm{~F}_{2} \text { (Ditte). } \\
77 \cdot 42\end{array}$ \\
\hline $0 \ldots \ldots$ & - & - & $10 \cdot 32$ \\
\hline $\mathbf{F} \ldots \ldots$ & $25 \cdot 73$ & $24 \cdot 05$ & $12 \cdot 26$ \\
\hline & $99 \cdot 76$ & $100 \cdot 00$ & $100 \cdot 00$ \\
\hline
\end{tabular}

The results comparatively stated are as follows:-

This shows that the green powder in question is uranous fluoride, $\mathrm{UF}_{4}$, and not $\mathrm{UO}_{2} \mathrm{~F}_{2}$, the difference between the found and calculated proportions being mainly due to the presence of free hydrofluoric acid.

Uranous fluoride is-as described by Bolton-insoluble in water, hardly attacked by weak acids, and is only with difficulty dissolved by concentrated acids. Heated on platinum-foil it loses fluorine, and, without melting, gives $\mathrm{U}_{3} \mathrm{O}_{8}$.

a-Uranium Oxyfluoride.-The most remarkable property of uranous fluoride is one described by Ditte as pertaining to $\mathrm{UO}_{2} \mathrm{~F}_{2}$, viz., the formation of a white crystalline "sublimate" on heating the substance in a closed crucible. The crystalline mass is very bulky, but extremely light, and it usually contains a quantity of very minute crystals of $\mathrm{UO}_{2}$. The quantity obtained depends on the manner in which the crucible containing $U F_{4}$ is heated, and. when a certain amount has been obtained, it cannot be increased by continued heating, 
but begins to decompose. If, however, at this point the crucible be allowed to cool, the crop of crystals removed, and the heating renewed, a further quantity of crystals can be obtained, and in this way as many as five crops have been yielded. It is evident from these facts that a certain amount of oxygen is necessary for the process, whilst an excess causes a different decomposition, viz., the conversion of $\mathrm{UF}_{4}$ into $\mathrm{U}_{3} \mathrm{O}_{8}$.

The preparation of this white crystalline compound in quantity presents great difficulties; the fact of its being prepared from a fused fluoride forbidding the use of any but platinum apparatus, and, as just pointed out, only a limited amount of oxygen must be present.

No more successfnl method was found than that of heating about 1 gram of uranous fluoride in a platinum crucible of the ordinary size, raising the temperature as quickly as possible, and leaving the mass to cool at the end of five minutes.

After the fourth application, the fluoride acquires the appearance of green sealing-wax, and begins to yield crops of crystals. The final residue in the crucible seems to consist chiefly of $\mathrm{UO}_{2}$. Many repetitions of the above process are necessary in order to obtain a sufficient quantity of the substance for analysis, and, as it is very hygroscopic, it is first necessary to estimate the amount of water present by heating with anhydrous sodium carbonate as previously described. When freshly prepared the substance is anhydrous.

The following is the result of an analysis:-

0.167 gram gave 0.0137 gram $\mathrm{H}_{2} \mathrm{O} ; 0.51$ gram gave 0.4235 gram $\mathrm{U}_{2} \mathrm{O}_{5}$ and 0.1122 gram $\mathrm{CaF}_{2}$. This corresponds to the composition $\mathrm{UO}_{2} \mathrm{~F}_{2}$ for the anhydrous body.

Ditte assigned to it the formula $\mathrm{UOF}_{4}$, and gave the following equation of formation, which he verifies by weighing the products from a known weight of the green powder :- $2 \mathrm{UO}_{2} \mathrm{~F}_{2}=\mathrm{UOF}_{4}+\mathrm{UO}_{2}+\mathrm{O}$. As the green powder has been shown to be $\mathrm{UF}_{4}$, the equation cannot hold good.

The following is a comparison of results :-

\begin{tabular}{|c|c|c|c|}
\hline \multirow{4}{*}{$\begin{array}{l}\mathrm{U} \ldots \ldots \\
\mathrm{O} \ldots \ldots \\
\mathrm{F} \ldots \ldots\end{array}$} & \multirow[b]{2}{*}{$\begin{array}{l}\text { Found. } \\
77.57\end{array}$} & \multicolumn{2}{|c|}{ Calculated. } \\
\hline & & $\begin{array}{l}\mathrm{UO}_{2} \mathrm{~F}_{2} . \\
77 \cdot 42\end{array}$ & $\begin{array}{c}\mathrm{UOF}_{4} \text { (Ditte) } \\
72 \cdot 29\end{array}$ \\
\hline & $10 \cdot 74$ (diff.) & $10 \cdot 32$ & 4.82 \\
\hline & $11 \cdot 69$ & $12 \cdot 26$ & $22 \cdot 89$ \\
\hline & $100 \cdot 00$ & $100 \cdot 00$ & $100 \cdot 00$ \\
\hline
\end{tabular}

$x$-Uraninm oxyfluoride is exceedingly soluble in water, giving a yellow solution. Heated in air it is gradually converted into the green oxide. An attempt to volatilise it in a current of carbon 
dioxide failed, the body only undergoing a slight change when heated above its temperature of formation. If a considerable quantity of a solution of the normal and acid fluoride of potassium be added to a solution of $\alpha$-uranium oxyfluoride, and the mixture gently evaporated, well-defined yellow crystals of quadratic potassium fluoxyuranate, $\mathrm{UO}_{2} \mathrm{~F}_{2}, 3 \mathrm{KF}$, are deposited. The crystallography of this latter compound has been carefully studied by Baker (Chem. Soc. J., Nov., 1879), and I have, fortunately, had his evidence as to the identity of the salts.

B-Uranium Oxyfluoride, $\mathrm{UO}_{2} \mathrm{~F}_{2}$. -The yellow solution formed in addition to uranous fluoride by the action of hydrofluoric acid on the green oxide was heated to expel excess of acid and allowed to evaporate. A pale-yellow saponaceous mass remained. Evaporated under different circumstances in air, by heat, or in vacuo over sulphuric acid and lime, in one case only was there a deposit obtained which could be called even semi-crystalline. In this case there were formed scales of a nacreous lustre resembling cadmium bromide. The semi-crystalline mass was dried at $100^{\circ} \mathrm{C}$. and analysed with the following results :-

0.3200 gram gave 0.3000 gram $\mathrm{U}_{2} \mathrm{O}_{5}=80.34$

$0.8185 \quad, \quad 0.7590 \quad, \quad,=79.49\} 79.91$ per cent. $\mathrm{U}$.

$\left.0.3670 \quad, \quad, 0.0734 \quad, \quad \mathrm{CaF}_{2}=9.75\right\}$

$0.4035 \quad " \quad " 0.0875 \quad " \quad,=10.59\} 10.17$ per cent. $\mathrm{F}$.

The following is a comparison of results with those of previous observers :-

\begin{tabular}{|c|c|c|c|}
\hline \multirow[b]{3}{*}{ U... } & \multirow{3}{*}{$\begin{array}{l}\text { Found. } \\
79 \cdot 91\end{array}$} & \multicolumn{2}{|c|}{ Calculated. } \\
\hline & & $\mathrm{JO}_{2} \mathrm{~F}_{2}$ (Bolton). & $\mathrm{UF}_{6}, 8 \mathrm{HF}$ (Ditte). \\
\hline & & $77 \cdot 42$ & 46.59 \\
\hline $0 \ldots$ & $9 \cdot 87$ (diff.) & $10 \cdot 32$ & - \\
\hline $\mathrm{F} \ldots$. & $10 \cdot 71$ & $12 \cdot 26$ & $51 \cdot 85$ \\
\hline H... & trace & - & $1 \cdot 56$ \\
\hline & $100 \cdot 00$ & $100 \cdot 00$ & $100 \cdot 00$ \\
\hline
\end{tabular}

Bolton did not analyse the substance.

These results, whilst disagreeing entirely with those of Ditte, do not exactly correspond with the composition $\mathrm{UO}_{2} \mathrm{~F}_{2}$, probably because on heating for some time at $100^{\circ}$ the body loses fluorine-a process which continues as the temperature is raised until the whole is converted into $\mathrm{U}_{3} \mathrm{O}_{8}$.

Another portion of the yellow solution was evaporated over sulphuric acid and lime until the weight remained constant. The residue was analysed with the following results :- 
0.8495 gram gave 0.6899 gram $\left.\mathrm{U}_{2} \mathrm{O}_{5}=69 \cdot 60\right\}$

$0.7315, \quad, 0.5899 \quad, \quad, \quad=69 \cdot 12\} 69 \cdot 36$ per cent. U.

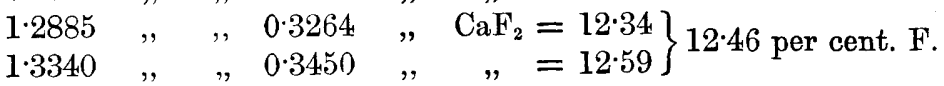

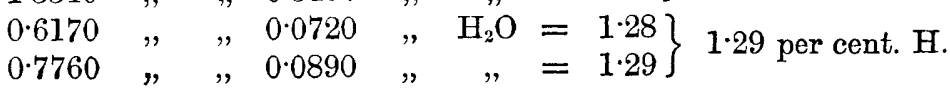

If the difference be regarded as oxygen the above analysis corresponds fairly well with a molecular formula $\mathrm{UO}_{2} \mathrm{~F}_{2}, \mathrm{HF}, \mathrm{H}_{2} \mathrm{O}$. Calculating the uranium as oxyfluoride and the excess of fluorine as hydrofluoric acid, and the remainder of the hydrogen as water, we obtain the following :-

$$
\begin{array}{rr}
\mathrm{UO}_{2} \mathrm{~F}_{2} \ldots \ldots \ldots & 89.59 \\
\mathrm{HF} \ldots \ldots \ldots & 1.56 \\
\mathrm{H}_{2} \mathrm{O} \ldots \ldots \ldots \ldots & 10.89
\end{array}
$$

This result, although from the nature of the case only approximate, is, when taken in conjunction with the previous analysis of a dried specimen of the compound, sufficient to show that the yellow liquid obtained on treating $\mathrm{U}_{3} \mathrm{O}_{8}$ with hydrofluoric acid, consists of a solution of oxyfluoride of uranium, $\mathrm{UO}_{2} \mathrm{~F}_{2}$.

Heated on platinum-foil, $\beta \mathrm{UO}_{2} \mathrm{~F}_{2}$ gives $\mathrm{U}_{3} \mathrm{O}_{8}$; in a closed crucible it undergoes decomposition more slowly, giving the dioxide. It is extremely soluble in water and alcohol, and gives potassium fluoxyuranate when its solution is evaporated with a mixture of normal and acid potassium fluorides.

It is evident therefore that the solutions of $\alpha$ - and $\beta$-oxyfluorides possess the same properties, and it is important to note the analogy presented here by uranium with another member of the group to which it has been finally relegated. Molybdenum oxychloride also exists in two isomeric forms, $\alpha$ and $\beta$, the former of which can be prepared by heating the chloride in air, an operation analogous to the preparation of $\alpha$-uranium oxyfluoride from uranous fluoride.

\section{The Fluorine Compounds of Uranium with the Alkalis.}

In a further paper (Compt. rend., 91, 166) Ditte describes new fluorine compounds of uranium and the alkalis. The salts previously known comprised two classes, the uranofluorides and the fluoxyuranates. The former were discovered by Bolton (Zeitsch. f. Chem., N.S. [2], 353), and included two with the formulæ $\mathrm{UF}_{4}, \mathrm{KF}$ and $\mathrm{UF}_{4}, \mathrm{NaF}$. The formation of the fluoxyuranates was first described by Berzelins (Lehrb. d. Chem. [iii], 1099, 1845), and the compounds afterwards examined by Bolton (loc. cit.), who obtained the potassium, 
sodium, and ammonium compounds. The fluoxyuranates were further investigated by Baker (Chem. Soc. J., Nov. 1879), who showed that the potassium salt exists in three modifications, $\mathrm{UO}_{2} \mathrm{~F}_{2}, 3 \mathrm{KF}$, $2 \mathrm{UO}_{2} \mathrm{~F}_{2}, 5 \mathrm{KF}$, and $2 \mathrm{UO}_{2} \mathrm{~F}_{2}, 3 \mathrm{KF}, 2 \mathrm{H}_{2} \mathrm{O}$, crystallising respectively in the quadratic, triclinic, and monoclinic systems.

The Series $\mathrm{UO}_{2} \mathrm{~F}_{2} .4 \mathrm{MF}$ of Ditte.-By fusing the green uranoso-uranic oxide, $\mathrm{U}_{3} \mathrm{O}_{8}$, with an alkaline fluoride, Ditte claims to have prepared a series of insoluble crystalline salts of the general formula $\mathrm{UO}_{2} \mathrm{~F}_{2}, 4 \mathrm{MF}$. The methods of preparation described by him have been followed in every particular, and compounds have been obtained which correspond in appearance with his descriptions. By adding $\mathrm{U}_{3} \mathrm{O}_{8}$ to fused potassium fluoride rendered feebly alkaline by the addition of potassium carbonate, and heating over the blowpipe for a short time, a yellow mass is obtained, which on lixiviation with water leaves undissolved transparent golden-yellow crystalline plates. These are insoluble in hot or cold water, but are readily dissolved by dilute acids. They are unaltered by heating in air, but when heated in a current of hydrogen, they acquire a greenish-black colour without altering their form. The crystals consist of thin plates, often with hexagonal outlines, and belong to the rhombic system. They are feebly dichroic, and exhibit a banded twin structure, which becomes very distinct in polarised light. The bands run in three systems parallel to the sides of the hexagon, and in addition there is a series of less regular markings at right angles to one edge. The two optic axes are visible in the polariscope, and their plane is apparently perpendicular to that of the plate.

The sodium salt is prepared in a precisely similar manner, and has a similar appearance, except that the crystals are smaller and have a deep orange colour. An attempt to prepare the lithium salt has not yet proved successful.

Although these salts correspond exactly in appearance with those described by Ditte as $\mathrm{UO}_{2} \mathrm{~F}_{2}, 4 \mathrm{KF}$ and $\mathrm{UO}_{2} \mathrm{~F}_{2}, 4 \mathrm{NaF}$, when an attempt was made to estimate the fluorine, only 0.1 or 0.2 per cent. was found. And indeed specimens have been prepared in which no trace of fluorine could be detected, the presence of this element apparently arising from imperfect washing, which with the sodium salt is very liable to be the case, owing to the sparing solubility of sodium fluoride.

These compounds present many points of similarity to the crystalline uranates described by Zimmermann (Ber., 14, 440), and their composition, so far as it has been determined, approaches to that of the diuranates, or still more closely to that of the intermediate products obtained by Zimmermann in the preparation of those bodies. Further experiments on the formation and composition of the potas- 
sium uranium compounds are necessary, however, before coming to a definite conclusion.

The Series $\mathrm{UOF}_{4}, 4 \mathrm{MF}, x \mathrm{H}_{2} \mathrm{O}$ of Ditte.-If instead of using the normal fluoride of potassium, a mixture of $\mathrm{U}_{3} \mathrm{O}_{8}$ and the acid fluoride $\mathrm{KF}, \mathrm{HF}$ be fused, different results are obtained. If, as soon as the mass is just fused, it be allowed to cool, it appears of a bright green colour, and on treatment with water gives a yellow solution, and an insoluble green powder resembling uranous fluoride. If, however, the fusion of the mass be continued, the green colour is gradually changed to a pale yellow, and at this stage treatment with water effects almost complete solution. On still further heating, the colour becomes tinged with orange, until finally, after prolonged fusion, the crucible contains the crystalline compound which has just been described as resulting from the action of $\mathrm{U}_{3} \mathrm{O}_{8}$ on fused normal fluoride of potassium. An explanation of these changes will be offered immediately.

The yellow solutions obtained by lixiviating the fused masses, freed from insoluble substances by filtration, were left at rest after being slightly concentrated, or were evaporated on a water-bath. In both cases small but very well-defined transparent crystals were obtained. Under the microscope these were at once recognised as quadratic potassium fluoxyuranate, and analysis gave confirmatory results :-

$$
\begin{aligned}
& 1 \cdot 1755 \text { grams gave } 0.6898 \text { gram } \mathrm{U}_{2} \mathrm{O}_{5}=50.29 \text { per cent. } \mathrm{U} \text {. } \\
& 1 \cdot 1755 \quad " \quad, \quad 0.6255 \quad, \quad \mathrm{~K}_{2} \mathrm{SO}_{4}=23.90 \quad, \quad \mathrm{~K} \text {. } \\
& 0.6720 " \quad \text { " } 0 \cdot 2648 \quad " \mathrm{CaF}_{2}=19 \cdot 20 \quad \text { " } \quad \text { F. }
\end{aligned}
$$

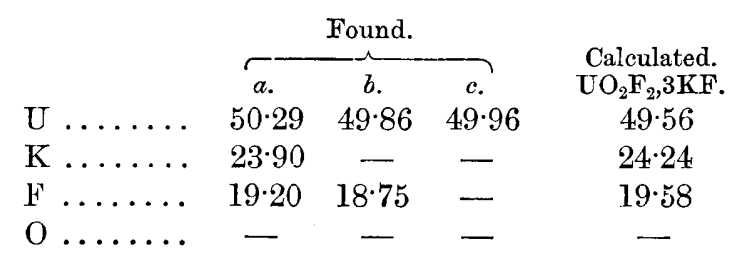

(b) and (c) are partial analyses of other specimens of the salt.

It appears therefore that when acid potassium fluoride and green uranoso-uranic oxide are fused together, the bydrofluoric acid of the acid salt is liberated, and acts on the oxide as shown in the first part of this paper, producing uranous fluoride, $\mathrm{UF}_{4}$, and $\beta$-uranium oxyfluoride, $\mathrm{UO}_{2} \mathrm{~F}_{2}$. In the early stages of the fusion, the former seems to unite with potassium fluoride to form the double salt $\mathrm{UF}_{4}, \mathrm{KF}$, whilst one molecule of $\mathrm{UO}_{2} \mathrm{~F}_{2}$ and three of $\mathrm{KF}$ form the fluoxyuranate. By further heating, the uranofluoride is converted into the fluoxyuranate, whilst the result of prolonged fusion of the latter is the 
insoluble crystalline compound, which is also obtained by using the normal instead of the acid potassium salt, and which contains no fluorine. This last change was noticed by Bolton (loc. cit.).

According to Ditte, the soluble yellow crystals obtained in the above operation have the formula $2\left(\mathrm{UOF}_{4}, 4 \mathrm{KF}\right) 3 \mathrm{H}_{2} \mathrm{O}$ or $\mathrm{UOF}_{4}, 4 \mathrm{KF}, 3 \mathrm{H}_{2} \mathrm{O}$, according to the temperature at which they are deposited, whereas my results show that they are the fluoxyuranate of potassium, $\mathrm{UO}_{2} \mathrm{~F}_{2}, 3 \mathrm{KF}$, already known. Moreover, Ditte adds that by adding caustic potash to the yellow solution obtained by treating $\mathrm{U}_{3} \mathrm{O}_{8}$ with hydrofluoric acid, the same bodies are produced, and that by dissolving them in water containing acid potassium fluoride, and recrystallising at a temperature of from $50-60^{\circ}$, a compound is obtained with the formula $\mathrm{UOF}_{4}, 4 \mathrm{KF}, \mathrm{H}_{2} \mathrm{O}$. This is opposed to the results obtained by Berzelius and Bolton, and to those detailed in the first part of this paper, for the yellow solution obtained by acting on $\mathrm{U}_{3} \mathrm{O}_{8}$ with hydrofluoric acid has been shown to contain uranium oxyfluoride. In addition it contains the excess of hydrofluoric acid employed, which would give potassium fluoride on treating the solution with caustic potash, and so lead to the formation of the salt $\mathrm{UO}_{2} \mathrm{~F}_{2}, 3 \mathrm{KF}$. When this salt is dissolved in water containing not more than 13 per cent. of acid fluoride of potassium the triclinic fluoxyuranate, $2 \mathrm{UO}_{2} \mathrm{H}_{2}, 5 \mathrm{KF}$, crystallises out (Baker, loc. cit.).

In no case have I obtained a salt corresponding in composition with either of the three formulæ given by Ditte, and it appears that the componnds obtained by him were in reality only the three fluoxyuranates already known.

\section{Postscript.}

In a recently published paper (Compt. rend., 95, 988), Ditte describes the "Preparation of some Crystallised Uranates in the Dry Way" by fusing a mixture of the alkaline (or alkaline-earth) chloride with green uranoso-uranic oxide, $\mathrm{U}_{3} \mathrm{O}_{8}$. No reference is made in the paper to the work done on this subject by Zimmermann (Ber., 14, 440; Annalen, 213, 290), who, following practically the same process, obtained widely different results. The latter chemist has shown that by fusing potassium or sodium chloride with $\mathrm{U}_{3} \mathrm{O}_{8}$, crystalline diuranates $\left(\mathrm{M}_{2} \mathrm{O}, 2 \mathrm{UO}_{3}\right)$ are obtained, but that lithium chloride under similar circumstances gives a normal lithium uranate, $\mathrm{Li}_{2} \mathrm{O}, \mathrm{UO}_{3}$. For an account of the precautions which were taken by Zimmermann in the study of these compounds, reference must be had to the original paper, where the modes of preparation and analysis are described in detail. Ditte, however, gives no analytical results in support of the correctness of his observations. 
It is also to be remarked that in an earlier paper (Compt. rend., 91, 166) previously referred to, Ditte claims to have obtained compounds which he formulates as double fluorides of uranium and the alkalis, by fusing alkaline fluorides with $\mathrm{U}_{3} \mathrm{O}_{8}$. In repeating these experiments I have succeeded only in obtaining bodies which approach the diuranates of Zimmermann in composition and properties. That such is likely to be the case might be inferred from the experiments of Zimmermann, and now of Ditte himself, since both prepare uranates or diuranates by fusing $\mathrm{U}_{3} \mathrm{O}_{8}$ with the haloïd salts of the alkalis. 